\title{
E1 Mediterráneo como frontera: desequilibrios territoriales y políticas migratorias ${ }^{1}$
}

\author{
The Mediterranean as Border: Territorial Imbalances and \\ Migration Policies
}

María Cristina Nin ${ }^{2}$

Stella Maris Shmite ${ }^{3}$

Para citar este artículo utilice el nombre completo así:

Nin, M. C. \& Shmite, S. M. (2015). El Mediterráneo como frontera: desequilibrios territoriales y políticas migratorias. Perspectiva Geográfica, 20(2), 339-364.

\section{Resumen}

Las características de las migraciones actuales llevan a repensar los conceptos geográficos vinculados con los migrantes y a definir las nuevas formas de construcción territorial que se originan con el desplazamiento de estos. Desde la perspectiva de la geografía crítica, que asume un compromiso ético con los problemas sociales contemporáneos, el propósito de este artículo es analizar la trayectoria de los migrantes en torno al Mediterráneo, donde se conforma un espacio geográfico único y un complejo entramado de dimensiones culturales, sociales, económicas, políticas y ambientales. Se analizan los nuevos escenarios que emergen en el contexto actual de las migraciones internacionales entre África y Europa, desde un abordaje político-normativo y socio-económico.

Palabras clave: África, Europa, Mediterráneo, migraciones.

1 Este artículo corresponde al Proyecto de Investigación Territorios Dinámicos, tramas complejas. Deconstruyendo las relaciones de poder, los actores y las tensiones en diferentes escalas, en el marco del Programa de Investigación Contextos territoriales contemporáneos: abordajes desde la Geografía (Resol. N093/14-CD-FCH-UNLPam).

2 Magister en Estudios Sociales y Culturales, Profesora en Geografía -Universidad Nacional de La Pampa. Profesora Asociada - Facultad de Ciencias Humanas - Universidad Nacional de La Pampa - Argentina. ninmcristina@gmail.com

3 Doctora en Estudios Sociales Agrarios - Universidad Nacional de Córdoba, Profesora en Geografía. Profesora Titular - Facultad de Ciencias Humanas -Universidad Nacional de La Pampa- Argentina. shmite_stella@yahoo.com.ar 


\begin{abstract}
The characteristics of present-day migrations led to re-thinking the geographical concepts related to migrants and to re-defining new ways of territorial construction which find their origins in the process of migrants' displacement. From the perspective of Critical Geography, that assumes an ethical compromise with contemporary social problems, the purpose of this article is to analyze the migrants' trajectories around the Mediterranean, where a unique geographical space and a complex network of cultural, social, economic, political and environmental dimensions is shaped. Following a political, legal and socioeconomic approach, this paper analyzes the new scenarios which emerge as part of the present context of international migrations between Africa and Europe.
\end{abstract}

Keywords: Africa, Europe, Mediterranean, migrations. 


\section{Introducción}

Las transformaciones en la sociedad contemporánea están asociadas a la existencia de tres grandes procesos globales: la internacionalización del capital, la difusión de los medios masivos de comunicación y el incremento de la intensidad y las formas de movilidad geográfica de la población. Dichos procesos están estrechamente interrelacionados y alteran la estructuración social en todos los lugares del mundo, con mayor o menor intensidad. Los actuales escenarios socioeconómicos tienen influencia en el modo de vida de los sujetos sociales; una de sus manifestaciones es la readecuación de los procesos productivos, y sus expresiones territoriales se manifiestan en la trama social del territorio, donde los sujetos buscan su bienestar, y el desplazamiento es un modo de lograr ese objetivo; por esta razón, la migración y el desarrollo son dos procesos fuertemente interrelacionados.

Si bien existen variantes en el origen $\mathrm{y}$ el destino de los migrantes, se identifican diferentes direcciones en estos desplazamientos: de Sur a Norte, de Sur a Sur, de Norte a Norte y de Norte a Sur ${ }^{4}$. La migración de

4 En el Informe sobre las Migraciones en el Mundo 2013 se adopta un enfoque amplio en el que se examina si el origen y el destino de los migrantes pueden producir diferentes resultados para ellos. "Por lo tanto, además de la migración Sur-Norte, el Informe analiza otras tres direcciones de la migración: de un país de ingresos altos a otro de la misma categoría (por ejemplo, del Reino Unido a Canadá -Norte-
Sur a Norte representa el $40 \%$ de los movimientos, de acuerdo con el Informe sobre Migraciones en el Mundo 2013 (OIM); una parte de este flujo corresponde al desplazamiento de África hacia a Europa a través del Mediterráneo.

El Mediterráneo, más que una barrera, ha supuesto un vínculo entre distintos países que ha propiciado el desarrollo de los desplazamientos humanos hasta tal punto que no se podría entender la vida cultural, política, social y económica de esta región sin el intercambio de personas que se ha producido históricamente desde unas regiones a otras (Algado Ferrer \& Ruiz Callado, 2009, p. 161).

La migración ${ }^{5}$ es un fenómeno que afecta el ámbito de actuación de la Unión Europea y de los Estados miembros, y que influye de manera creciente en el diseño de las políticas comunitarias de gestión de la inmigración. La presencia de trabajadores migrantes de origen africano representa un reto, tanto por la garantía

Norte-); de un país de ingresos altos a un país de ingresos bajos o medianos (por ejemplo, de Portugal al Brasil Norte-Sur-); y de un país de ingresos bajos o medianos a otro de esa misma categoría (por ejemplo, de Indonesia a Malasia-Sur-Sur-)" (OIM, 2013, p. 25). Esta denominación Norte-Sur, Norte-Norte, Sur-Norte y Sur-Sur implica una connotación política y económica.

5 De acuerdo con la Real Academia Española (RAE), migración se define como desplazamiento geográfico de individuos 0 grupos, generalmente por causas económicas o sociales. 
de los derechos humanos como por la integración social de los migrantes, incluso en lo que se refiere a sus derechos ciudadanos y de inclusión en las instituciones democráticas.

La migración internacional entre África y Europa, y sus características constituyen el eje de análisis de este artículo. Los migrantes son sujetos sociales que participan en forma consciente o (la mayoría de las veces) en forma inconsciente de las estrategias económicas y políticas a escala global, como parte de la trama social que se construye en determinados entornos económicos con marcados desequilibrios regionales. En este contexto, los migrantes africanos pueden considerarse nómadas del actual sistema capitalista.

En el análisis de los flujos migratorios internacionales se suele insistir más en las migraciones Sur-Norte, verticales o intercontinentales, pasando por alto las intracontinentales $\mathrm{u}$ horizontales ${ }^{6}$, que son las que registran los mayores desplazamientos en el mundo y que se producen entre las distintas regiones del Sur y entre países del mismo continente. Así, se pierde de vista que las poblaciones de África se desplazan a menudo dentro

6 Se denominan migraciones verticales o intercontinentales aquellas que implican el desplazamiento de población desde un continente a otro. Por su parte, las migraciones horizontales 0 intracontinentales son aquellas que se producen dentro de un país o dentro del mismo continente. de un mismo país (éxodo rural) o hacia los países limítrofes, casi igual de pobres que los países de partida. Las migraciones interafricanas involucran aproximadamente cuarenta millones de migrantes internos, que se desplazan por motivos políticos, económicos, culturales o medioambientales. África es el territorio donde predominan las migraciones forzadas o de personas que huyen por la persecución política, la violación de los derechos humanos y los conflictos armados (Kabunda Badi, 2012).

\section{África: predominio de los flujos intrarregionales}

Las migraciones se dan en todas las regiones del mundo, y África no es ajena a este proceso que va más allá de las fronteras estatales y que tensiona el concepto de Estadonación, con fronteras cerradas y una población homogénea. Los Estados son cada vez más multiétnicos y pluriculturales, con una fuerte presencia de diásporas que desarrollan sus actividades socioculturales propias. África ha sido históricamente, y sigue siendo, un continente de migraciones. La cultura del nomadismo, muy difundida entre los pueblos africanos, fue reforzada por la colonización europea con su política de reclutamiento de mano de obra para los cultivos de exportación y para las actividades mineras, portuarias y comerciales. Pero, sin dudas, es 
en el período poscolonial cuando se acentuaron las tensiones y conflictos que dan lugar a los desplazamientos de población.

En las últimas décadas se acentuaron las migraciones por causas vinculadas con la desertificación, fenómeno que acrecienta los movimientos de población hacia las áreas urbanas en busca de mejores posibilidades de subsistencia. La desertificación agrava los riesgos de inseguridad alimentaria, hambre, pobreza y crisis social. Este conjunto de problemáticas puede provocar tensiones sociales, económicas y políticas susceptibles de evolucionar en conflictos de intensidad imprevisible.

De igual modo, las guerras y los conflictos sociales han convertido a muchos países en expulsores de refugiados y migrantes hacia países limítrofes $\mathrm{u}$ otras regiones del continente (Kabunda Badi, 2008). Por lo tanto, la migración africana se explica desde múltiples variables. "De hecho, la explicación se encuentra en la interacción histórica entre los factores políticos, sociales, culturales y también medioambientales de los diferentes espacios migratorios" (Crespo Ubero, 2006, p. 78).

Las migraciones desde el campo a los centros urbanos concentran la mayor parte de los flujos migratorios en África. De hecho, las ciudades manifiestan un acelerado crecimiento demográfico en contextos de escaso desarrollo urbanístico. En este sentido, Cheru (2008) sostiene que pueden observarse dos tipos de urbanización diferentes: urbanización con desarrollo y urbanización sin desarrollo; esta última, dominante en África Subsahariana, se produce cuando la economía nacional y el desarrollo productivo son incapaces de responder a las necesidades de una población en constante aumento. Según Cheru:

En la mayoría de las ciudades africanas, las desigualdades aumentaron y se agravaron. $\mathrm{Si}$ bien éstas son anteriores a la fase actual de globalización, todas se vieron fortalecidas después de los años 80. La encarnecida competencia entre las ciudades con el fin de atraer capitales y empresas, y generar empleos y recursos suplementarios, no logró otra cosa que agravar las desigualdades entre los centros urbanos y los grupos sociales en su seno (Cheru, 2008, p. 48).

El aumento de la cantidad de migrantes africanos tiene mucho que ver, además de los factores económicos y políticos, con el uso de las nuevas tecnologías de comunicación, como internet y la telefonía móvil, y también con el aumento de las relaciones bilaterales entre Estados europeos y 
África (Crespo Ubero, 2006). En las últimas décadas, los flujos migratorios de África han acentuado el desplazamiento intracontinental, también denominado horizontal:

Las migraciones interafricanas abarcan a millones de personas y superan con creces las migraciones internas de otros continentes. [...] Dicho de otra manera, el grueso de los inmigrantes se queda en sus regiones respectivas (Kabunda Badi, 2012, p. 12).

Los patrones de migración dentro del continente son diversos y con múltiples destinos. También se observa que los flujos de salida no solo están orientados hacia Europa, sino también hacia Medio Oriente y América. Es de destacar que la emigración de los jóvenes africanos se ha convertido en un fenómeno masivo, y ante la imposibilidad de emigrar legalmente, por la dificultad que tienen para obtener los documentos requeridos, han optado por las vías ilegales de entrada a la Unión Europea (UE), ya sea por territorio español, francés o italiano, principalmente. Cabe distinguir la emigración de África del Norte de la de África Subsahariana, dado que, en opinión de Sami Naïr, África del Norte "blanca" (Egipto y Magreb) exporta sus poblaciones hacia Europa y Estados Unidos, mientras África Subsahariana, aunque orienta su emigración hacia Europa (sobre todo desde países como Ghana, Nigeria y Senegal), tiene importantes flujos migratorios internos: de las zonas rurales a las ciudades, de las zonas en guerra hacia las zonas en paz y de los países más pobres hacia los países más ricos (Naïr, 2006). Sin embargo, el escenario que se abrió a partir de la 'primavera árabe' en el norte de África dio lugar a una reconfiguración de la geografía migratoria del Mediterráneo, situación que pone en evidencia el dinámico y cambiante paisaje fronterizo (Ferrer Gallardo \& Kramsch, 2012).

\section{Las rutas de los migrantes. Travesías complejas con destinos inciertos}

Las rutas migratorias que atraviesan el desierto del Sahara corresponden a las milenarias trayectorias comerciales (Figura 1). Existen tres rutas clásicas que atraviesan el Sahara. La Atlántica, que parte de Senegal a Marruecos por la costa del Océano Atlántico; se trata de la más antigua. La Central, con Tombuctú y Gao, en Malí, como puntos de partida; es la ruta que centralizó el comercio transahariano de oro, sal y cobre; desde Agadez (Níger) hacia el norte se ramifica en dos: una se dirige hacia el norte a través de Libia, con destino a Trípoli (Libia) y luego a las islas de Lampeduza o Malta, en el Mediterráneo, y la otra lleva a Marruecos y Túnez, atravesando Argelia. La ruta Oriental es la que 
conecta Somalia con Libia, pasando por Jartum (Sudán), que también conecta con Oriente Medio pasando por El Cairo (Egipto), con destino a los países petroleros.

Si se tiene en cuenta esta diversidad de rutas transversales, el Sahara no puede ser considerado una barrera, sino, por el contrario, un territorio interior donde se desarrollan comunicaciones multidireccionales y multiculturales; por ejemplo, de norte a sur entre el Mediterráneo y el sur del Sahara; de este a oeste las migraciones milenarias desde el Nilo hacia el Atlántico; así como otras trayectorias en distintas direcciones, como las rutas comerciales y migratorias desde Senegal y Malí a Egipto e incluso hacia La Meca en la península arábiga. Además, es importante considerar que cada ruta era, y es, una vía de doble dirección. Son movimientos de ida y vuelta, incluso en las rutas actuales circulan migrantes en diferentes direcciones (Crespo Ubero, 2006).

Según el Informe sobre las Migraciones en el Mundo 2011 (OIM, 2011), unos 30 millones de africanos emigraron a otros países. Las dos terceras partes de los migrantes del África Subsahariana se trasladan a otros países de la región. El $64 \%$ de la migración en África Subsahariana es de carácter intrarregional y laboral, y se dirige principalmente a países como Burkina Faso, Kenya y
Sudáfrica. En África Occidental los flujos migratorios son predominantemente intrarregionales; más del $70 \%$ de los movimientos se localizan dentro de la región. En África Meridional y África Oriental, los movimientos interregionales representan el $66 \%$ y el $52 \%$ de los flujos migratorios, respectivamente.

Por el contrario, según el citado informe, la gran mayoría de los migrantes de África del Norte (90 \%) se dirigen a países ubicados fuera de la región. En general, alrededor de la mitad de los migrantes de África del Norte viven fuera del continente, la mayoría de ellos en Europa.

La trayectoria que siguen los migrantes dentro del territorio africano no está compuesta por un único viaje, sino que tiene etapas formadas por itinerarios complejos que intercalan desplazamientos $\mathrm{y}$ asentamientos temporarios. Estos sujetos migrantes no son totalmente nómades, suelen crear territorialidades dinámicas que algunos autores denominan espacios diaspóricos7 (Sow, 2007). Dentro del territorio africano se mueven verdaderos

\footnotetext{
7 "La migración de grandes masas hacia distintos puntos del planeta, la conservación de sus costumbres y tradiciones, los lazos permanentes con el lugar de origen y la adaptación o asimilación parcial a las sociedades de acogida, llevan a definir a estos grupos como diásporas, cuya existencia interroga los paradigmas que han servido para definir los conceptos de pertenencia, nación, identidad" (Fernández, 2008, p. 306).
} 


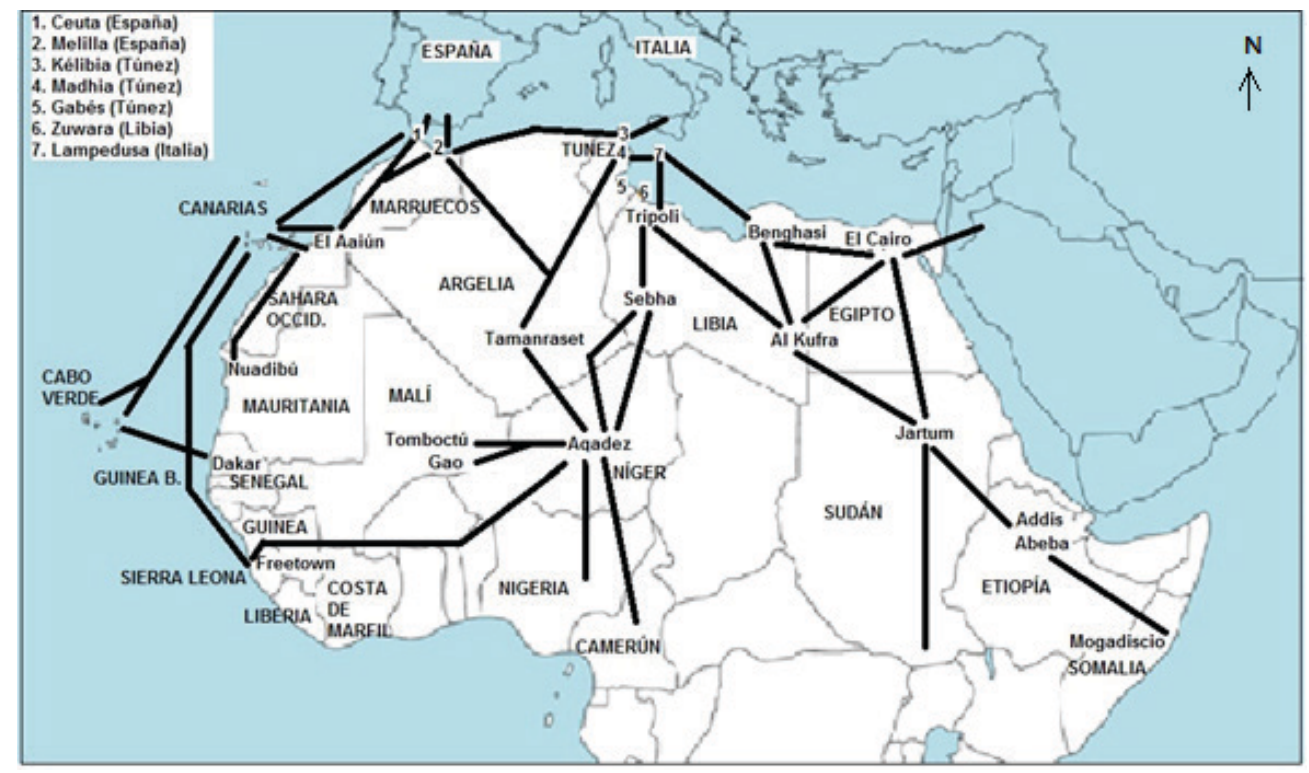

Figura 1. Rutas migratorias en el norte de África.

Fuente: Elaboración propia con base en Crespo Ubero (2006) y De Haas (2007).

enlaces sociales con diversas formas de relación entre los individuos (las diásporas) donde se tejen relaciones que se transforman diariamente.

El espacio diaspórico africano, organizado y modelado a través de prácticas materiales y de sistemas de símbolos, es ante todo, un encastramiento en las relaciones de redes sociales, un marco para observar la redefinición de las identidades, los enlaces de la proximidad y las diversas formas de interacción, redistribución y coordinación de los agentes. Los lugares se convierten en principios de sentidos (lugares de prácticas) para los que los dinamizan y hacen reflexionar y objetos de conocimiento para los que los observan y analizan (Sow, 2007, pp. 143-144).

El flujo de migrantes es continuo. En las ciudades del Sahel ${ }^{8}$ crece el

8 "La palabra Sahel en idioma árabe significa "borde" o "frontera", en referencia al borde continental sur del desierto de Sahara, donde comienza esta franja de clima semiárido caracterizada por un proceso de desertificación creciente. Es un territorio formado por Estados, en gran parte antiguas colonias, que se encuentran entre los más pobres del planeta. Son Estados mayoritariamente islámicos, con gobiernos débiles y fronteras extensas. Es un área inestable desde múltiples perspectivas (social, económica, política, militar) donde los gobiernos tienen muchas dificultades para ejercer el control y la gobernanza del territorio. [...] El Sahel está localizado al sur del desierto del Sahara y al norte de las sabanas y selvas del golfo de Guinea y África central. Es un área de transición entre el África del norte y África subsahariana. Corresponde a un territorio de unos 4 millones de $\mathrm{km}^{2}$, que se extiende desde océano Atlántico hasta el mar Rojo, y que ocupa parcialmente los siguientes países: Mauritania, Senegal, Malí, Burkina Faso, Níger, Nigeria, Chad, Sudán, Etiopía y Eritrea" (Shmite y Nin, 2015, p. 207). 
movimiento de personas en diferentes direcciones, y estos movimientos generan procesos sociales de carácter intercultural en ciudades como Tombuctú, Gao y Agadez, entre otras. En ellas se establecen migrantes, considerados “(...) aspirantes a llegar a Europa que no han conseguido su objetivo, porque han sido expulsados [...] o porque no han ganado todavía el dinero suficiente para hacer la gran travesía" (Crespo Ubero, 2006, p. 84).

El territorio se transforma permanentemente por el movimiento de los migrantes y las acciones de apropiación realizadas por ellos. En este sentido, la reterritorialización no se identifica con la sedentarización, sino con la movilidad de los migrantes. El territorio, en este caso, es un espacio donde no solamente viven los hombres, sino también donde transitan; está en pleno movimiento, y en él los inmigrantes construyen redes sociales diferenciadas y desarrollan actividades para sobrevivir y, en lo posible, reunir dinero para continuar el viaje o enviar a sus familiares (Sow, 2007):

Productoras de sociabilidades, las migraciones africanas fabrican continuamente unas territorialidades caracterizadas por tensiones entre la movilidad y el sedentarismo. [...] Los lugares que estos emigrantes cruzan, que les permiten contar y fabricar historias, también les dan oportunidad de materializar una existencia social, de hacerse una representación de sí mismos capaz de catalizar perpetuos procesos de recomposición territorial expansiva e identitaria (p. 146).

\section{Europa como destino}

El número de migrantes que abandonan el continente africano en dirección hacia Europa se ha acrecentado aceleradamente en las últimas décadas. Sin embargo, solo el $26,2 \%$ de los extranjeros en la Unión Europea son africanos (EUROSTAT, 2010). África Occidental y del Norte han sido las regiones donde se originan la mayor cantidad de inmigrantes hacia Europa. Los principales países de procedencia son: Senegal, Gambia, Sierra Leona, Liberia, Malí, Costa de Marfil, Ghana, Nigeria, República Democrática del Congo, Camerún, Sudán y los países del Cuerno de África. De acuerdo con lo expresado por De Haas (2007), se estima que entre 65.000 y 120.000 africanos subsaharianos acuden cada año a los países del Magreb por tierra, pero solo entre el $20 \%$ y el $38 \%$ de ellos ingresan en Europa. El número de subsaharianos que logran cruzar ilegalmente a Europa, de acuerdo con estimaciones, es del orden de 25.000 a 35.000 cada año. La mayoría de 
los inmigrantes entran legalmente en Europa y se mantienen hasta la expiración de su visa.

Gran parte de los migrantes son jóvenes de entre veinte y treinta años. Álvarez Acosta (2011) sostiene que el $60 \%$ tienen un nivel escolar de bachiller y el $31 \%$ corresponde a personal calificado. El $30 \%$ de la mano de obra altamente calificada trabaja fuera del continente. En este sentido, el fenómeno de la "fuga de cerebros", o sea la pérdida de capital intelectual africano, tiene un impacto negativo en el desarrollo del continente, por constituir una importante pérdida económica y social (Kabunda Badi, 2008). Esta situación contribuye a profundizar las desigualdades internas de África, dado que los recursos humanos que tuvieron oportunidades de formarse en los países africanos deciden abandonar África para insertarse en mejores condiciones económicas en otros países. De este modo, no se acrecienta el capital social local y se acentúan las necesidades y las desigualdades en la población, lo que representa un costo social y económico muy elevado para este continente. Respecto a la formación profesional, se puede afirmar que “(...) hay más científicos, ingenieros y otros cuadros africanos en Estados Unidos que en África [...] una verdadera hemorragia cerebral o lo que algunos califican de saqueo o de la trata de cerebros" (Kabunda Badi, 2008, p. 17). La emigración de profesionales se explica por una conjunción de razones económicas, políticas y sociales, así como por la ausencia de inversiones en investigación y estructuras científicas, entre otras. Aquellos profesionales que se insertan en los países del Norte tienen más posibilidades de conseguir ciudadanía y, por como consecuencia, no regresan a su país de origen.

Respecto al concepto de capital social, es importante tener en cuenta que la red de vínculos entre los sujetos sociales, basados en la confianza y la reciprocidad, constituye una de sus múltiples dimensiones. Este concepto toma mayor fuerza cuando comienza a ser aplicado como eje de las propuestas de desarrollo territorial, particularmente en la década de los noventa, tanto en Europa como en Latinoamérica. La bibliografía es abundante en torno a este concepto, y varios autores lo abordan desde diferentes perspectivas. Para Bourdieu (2008), el capital social se define como el agregado de recursos reales o potenciales, ligados a la posesión de una red durable de relaciones sociales más o menos institucionalizada de reconocimiento mutuo. En expresiones de Coleman (1990), el capital social reside en los recursos socio-estructurales, los que constituyen un activo de capital para el individuo y facilitan ciertas acciones comunes de los agentes dentro de la estructura (Durston, 2000). Para este último autor, el concepto de capital social debe entenderse 
como “(...) el contenido de ciertas relaciones y estructuras sociales, es decir, las actitudes de confianza que se dan en combinación con conductas de reciprocidad y cooperación" (Durston, 2002, p. 15). Los procesos migratorios en África desestructuran el capital social, lo que representa una problemática más para las comunidades locales.

La inmigración en la Unión Europea (UE) en la actualidad presenta dos tendencias contradictorias. Por un lado, el ingreso de inmigrantes constituye un flujo continuo, pero, por otro lado, las políticas de inmigración implementadas por los países de la UE limitan cada vez más el ingreso de extranjeros. En relación con el primer punto, la UE es la región que ocupa el primer lugar en el mundo como receptora de extranjeros. Siendo Italia y España los países que reciben mayor número de inmigrantes. En cuanto al marco legal de la UE, la evolución de la normativa vinculada con las políticas migratorias se puede agrupar en tres períodos: el primero, de 1945 a 1973, denominado de "Puertas Abiertas"; el segundo, de 1973 a 1992, de "Puertas Cerradas", y desde 1992, la "Europa Fortaleza".

El período de "Puertas abiertas" se enmarca en el crecimiento económico de la posguerra, que demandó un flujo significativo de migrantes de distintos países. Los países receptores de Europa occidental impulsaban el ingreso de extranjeros en su calidad de mano de obra, para dar respuesta a la creciente demanda del crecimiento económico de la posguerra. En este sentido fue muy importante el aporte de Europa del sur, entre los que se destacan los migrantes del sur de Italia y de España (2.000.000 de personas), yugoslavos (1.500.00), griegos (500.000) y también turcos (1.000.000); no menos importante fue la llegada de inmigrantes de las excolonias, como los provenientes de la Commonwealth ${ }^{9}$ al Reino Unido (1.500.000), magrebíes a Francia (1.000.000) e indonesios a Holanda (Zamora, 2003). El modelo "fordista" de producción, de grandes unidades de producción basadas en el trabajo en cadena y la fabricación de bienes de consumo para las masas de obreros, se afianza en varios países de Europa Occidental. Este proceso fue acompañado por la regulación económica a través de la intervención estatal y los pactos sociales entre los sindicatos y los empresarios, lo que favoreció la construcción del Estado de Bienestar. Este modelo de acumulación capitalista sufre una crisis profunda a inicios de los años setenta, crisis que es conocida como la "crisis del petróleo" (1973); es a partir de esta década

9 La Commonwealth (Mancomunidad de Naciones), denominada también Mancomunidad Británica de Naciones, es una organización integrada actualmente por 53 países, de los cuales solo Mozambique y Ruanda no tienen vínculos con la colonización británica. El objetivo principal de esta organización es propiciar la cooperación económica y política entre los Estados miembros. 
cuando comienzan las restricciones al ingreso de extranjeros.

El segundo período, de "Puertas Cerradas" (1973 a 1992), se identifica con el inicio de las políticas migratorias; se origina como respuesta a la triple crisis (productiva, financiera y fiscal), cuando las políticas estatales se orientan a la privatización y reducción de la intervención, se recortan las prestaciones del Estado de Bienestar $\mathrm{y}$, como elemento clave, se flexibiliza el mercado laboral. Por esta razón, en los países más industrializados de Europa se inicia, a partir de 1973, un período de restricciones a las migraciones y se propicia el retorno de los migrantes a su país de origen. Las limitaciones al ingreso de extranjeros modifican el tipo de flujo de migrantes (legales a ilegales) y comienza a ocupar la escena pública el migrante clandestino. Por tal motivo, en el contexto de la Comunidad Europea se construye paulatinamente la representación de la inmigración como un problema. Entre 1973 y 1992 se van a implementar una serie de normas con el propósito de controlar el flujo de extranjeros hacia los países europeos. Paralelamente a la liberalización de los movimientos y las posibilidades de cambio de residencia para los ciudadanos de los países miembros, se fortalecieron los controles y los ingresos para las personas procedentes de países no miembros. La creación de una "Europa Fortaleza" parece estar destinada a sostener el Modelo Social Europeo, es decir, el espacio de prosperidad económica con garantías sociales y jurídicas, frente al avance de los extranjeros provenientes de países pobres, percibidos como una amenaza.

En los años noventa se inicia el tercer período, asociado a los intentos de los países europeos por definir normativas comunes frente a la problemática de las migraciones; así, se aceleró el proceso de construcción de una Política Migratoria Común, cuyos fundamentos se formularon por primera vez en el Tratado de Maastricht (1992). A partir de este momento Europa se presenta ante el mundo como una "fortaleza", con muros legales y, también, físicos difíciles de sortear. A partir de la aprobación del Tratado de la UE, celebrado en Maastricht, el tema de las migraciones se incorpora a la normativa y se constituye en uno de los pilares de la UE, vinculado con la justicia y los asuntos internos. Por primera vez se considera de interés de todos los Estados miembros la política de inmigración, en especial lo relacionado con el ingreso, estadía y trabajo irregular de inmigrantes provenientes de terceros Estados. Es importante destacar que en esta política se sientan las bases de la ciudadanía europea y la distinción entre ciudadanos europeos y ciudadanos extracomunitarios (Brumat, 2013). 
A partir de la década de los noventa, el recorrido normativo y las acciones en torno a la problemática de las migraciones se pueden sintetizar en la siguiente cronología:

En 1995 se crea en Barcelona la Asociación Euromediterránea, cuyo propósito prevé acuerdos bilaterales y regionales para promover el desarrollo económico de los países al Sur del Mediterráneo.

En 1997, con el Tratado de Ámsterdam, se incorpora el tratamiento común de los trámites de asilo y de inmigración y se unifica bajo una misma normativa el visado, asilo, inmigración y otras cuestiones vinculadas con la circulación de personas. Lo más destacado es el fortalecimiento del Acuerdo Schengen ${ }^{10}$ (1995), un territorio donde se suprimen las fronteras internas y se unifican las políticas de visado $^{11}$, así como los requerimientos de entrada de extranjeros.

En 1999, en el Consejo Europeo de Tampere se aprobó un sistema común

10 Espacio Schengen es un acuerdo por el que varios países de Europa han suprimido los controles en las fronteras interiores y han trasladado los controles a las fronteras exteriores (con terceros países terceros). Toda persona que haya entrado regularmente por una frontera exterior o resida en uno de los países que aplican el Acuerdo, puede circular libremente.

11 Forman parte de este territorio Alemania, Austria, Bélgica, Dinamarca, Eslovaquia, Eslovenia, España, Estonia, Finlandia, Francia, Grecia, Países Bajos, Hungría, Islandia, Italia Letonia, Liechtenstein, Lituania, Luxemburgo, Malta, Noruega, Polonia, Portugal, República Checa, Suecia y Suiza. de asilo, con el complemento de una política de incentivo a la migración legal y de lucha contra la migración ilegal (Programa de Tampere 19992005). Esta normativa común tenía como propósito la creación de un espacio interno de libertad, seguridad y justicia.

En el año 2000, mediante el Tratado de Niza se estableció un sistema de cooperación policial y judicial en aspectos penales, así como normativa vinculada con la prevención y resolución de acciones de racismo y xenofobia.

En el año 2001, como consecuencia de los atentados terroristas registrados en Estados Unidos, el control de los migrantes se incrementó considerablemente, tanto para el ingreso como para la permanencia de los migrantes existentes en los países de la UE.

En 2002 se celebra la Cumbre de Sevilla, donde el problema de la inmigración comienza a ocupar un lugar relevante en la agenda europea. El Consejo Europeo elaboró el Libro Verde, relativo a la política comunitaria de retorno de los residentes ilegales. El propósito de este instructivo fue lograr la cooperación común de los países miembros en lo concerniente al retorno de los residentes ilegales, así como la definición de una política de readmisión en acuerdo con los países de origen. 
Para esta fecha, en la UE residían 18 millones de inmigrantes registrados y unos 3 millones de indocumentados, siendo España, Italia, Alemania y Reino Unido los países con mayor número de inmigrantes.

En 2003 se elabora el Programa de La Haya, denominado Consolidación de la Libertad, la Seguridad y la Justicia en la Unión Europea. En este programa, que se aprobará al año siguiente, reviste particular importancia la profundización de la Política Común de Migración y Asilo.

En 2004, el Consejo Europeo, reunido en La Haya, aprueba el Programa de la Haya (2005-2009), que establece un marco normativo sobre el tratamiento de la inmigración, la integración de los inmigrantes y la seguridad de las personas. Se establece como prioridad un planteamiento global del fenómeno migratorio. Dicho Programa diseñó las acciones por desarrollar en los siguientes cinco años con el propósito de construir un espacio común de libertad, seguridad y justicia. Entre las prioridades se acentúa la necesidad de una mayor cooperación comunitaria con terceros países en lo relacionado con la readmisión y el retorno de los migrantes al país de origen. Entre las políticas comunes internas, este Programa se propone:

- Reforzar los derechos fundamentales y la ciudadanía europea
- Luchar contra el terrorismo

- Definir un enfoque equilibrado de la inmigración

- Gestionar de forma integrada las fronteras exteriores ${ }^{12}$

- Elaborar un procedimiento común en materia de asilo

- Maximizar las repercusiones positivas de la inmigración y definir un marco europeo de integración multicultural.

Por otra parte, también en 2004 fue creada la Política Europea de Vecindad, en reemplazo de la Asociación Euromediterránea; constituye un programa de acción exterior de importancia fundamental, relacionada en forma indirecta con la problemática de la inmigración. El objetivo central es profundizar las relaciones económicas y políticas con los países del entorno europeo oriental y meridional, para mejorar la estabilidad y seguridad común.

También en 2004, y en relación con el punto anterior, se reglamenta la financiación de acciones vinculadas con el tema de migraciones y desarrollo a través del Programa de Asistencia Financiera y Técnica

12 Creación de la Agencia Europea para la Gestión de la Cooperación Operativa en las Fronteras Exteriores FRONTEX (2004)-, cuya función estuvo inicialmente más enfocada al patrullaje de la frontera marítima sur (Mar Mediterráneo), considerada la ruta más utilizada por los migrantes africanos, aunque actúa en todo el entorno del espacio Schengen. 
de los terceros países en lo relativo a migración y asilo, denominado Programa AENEAS.

En 2005 se introducen en el debate sobre la inmigración nuevas líneas de tratamiento: las Políticas de Desarrollo. Al respecto se publica un documento específico sobre las acciones prioritarias en África y el Mediterráneo.

También en 2005, y en este proceso de construcción de una política común en materia de inmigración irregular, la Comisión Europea presentó una propuesta vinculada con los procedimientos y normas comunes por aplicar para el Retorno de los nacionales de terceros países que se encuentren ilegalmente en el territorio de los Estados miembros.

En esta misma línea de trabajo, en 2006 se publican las propuestas sobre el tratamiento integral de la inmigración (Planteamiento Global), que serán aprobadas por el Consejo Europeo.

En 2006, la Comisión Europea constituyó el Grupo de Comisarios sobre Asuntos de Inmigración, que agrupa el tratamiento de todos los aspectos vinculados con la inmigración: Asuntos de Justicia e Interior, Desarrollo, Empleo, Educación y Formación, Política Regional, Asuntos Económicos, Relaciones
Exteriores y Política Europea de Vecindad (Frattini, 2007).

En 2006 se celebró la Conferencia Euro-Africana sobre Migración y Desarrollo, en Rabat, que culmina con la Declaración de Rabat. La propuesta es potenciar la cooperación entre los países de origen, tránsito y destino para lograr una gestión integral de las migraciones. Se introduce la idea de corresponsabilidad entre los países involucrados.

En 2007 se pone en marcha el Programa de Cooperación 2007-2013 con los países integrados en la Política Europea de Vecindad; este es un instrumento financiero para actuar como nexo entre migraciones y desarrollo, promover la migración laboral legal, luchar contra la inmigración ilegal, proteger a los migrantes contra la explotación y promocionar el asilo.

En el año 2008 se firmó el Pacto Europeo sobre inmigración y asilo, en el que se acordó que los países de la UE debían favorecer el aprendizaje de la lengua, el acceso al empleo y el respeto por las identidades y los valores. Este pacto, propuesto por Francia, impulsa la lucha contra la migración ilegal e incentiva a reforzar la eficacia de los controles fronterizos.

En 2008 se aprobó la Directiva de Retorno, luego de tres años de extensos debates; tiene como objetivo 
unificar los procedimientos, tiempos y métodos de repatriación de los inmigrantes irregulares en los países de la Unión Europea (Brumat, 2013). La aplicación de esta normativa comenzó en 2010.

El recorrido a través del proceso de construcción del entramado de acciones institucionales y aprobación de normas, expresado en los párrafos anteriores, da cuenta de la preocupación que representa la inmigración en la Unión Europea y de la necesidad de implementar acciones cada vez más restrictivas. El abordaje de esta problemática ha demandado amplios debates en las instituciones europeas, y sucesos como los atentados terroristas en Estados Unidos y en países europeos, así como la crisis económica iniciada en 2008 , derivaron en el endurecimiento de las normas de control de la inmigración ilegal.

La Unión Europea ha instalado en la agenda política el tema del control de los extranjeros ilegales, y en los últimos años, la inmigración se transformó en un problema prioritario en la agenda de seguridad interior, lo cual se evidencia en el control de las fronteras con un amplio despliegue económico, militar y diplomático.

\section{El Mediterráneo: ¿puente o área de ruptura?}

El Mediterráneo constituye una de las zonas de circulación de las poblaciones que intentan mejorar sus condiciones de vida, por lo que esta ruta migratoria se transforma en una zona de ruptura y, al mismo tiempo, de contacto entre países pobres y países ricos -África y Europa, ubicadas frente a frente- (Naïr, 2006). Entre otras zonas que presentan estas características se pueden mencionar: Asia y los países del Golfo, México y la frontera con América del Norte, Asia y el Pacífico Americano y los países de Europa del Este con Europa Occidental. Estas áreas son denominadas por Naïr, "zonas de ruptura", debido a que en ellas se produce el conflictivo contacto entre la pobreza y la riqueza y son también donde " [...] se alzan con más altura las murallas contra los inmigrantes" (Naïr, 2006, p. 37). El Mediterráneo, como área de frontera, puede ser considerado un objeto geográfico que separa dos regiones. De acuerdo a lo expresado por Papadodima,

Este objeto no se resume en un límite, porque hay incidencias sobre la organización del espacio (efectos-frontera) e integra una dimensión política (es decir, lo que compete a la estructuración de una sociedad), una dimensión simbólica (es reconocida como un conjunto de actores y sirve de indicador en el espacio), y una dimensión material (que está inscrita en el paisaje) (Papadodima, 2011, p. 191). 
Si bien los flujos migratorios en el Mediterráneo desde el sur hacia el norte se han profundizado en los últimos años, son importantes desde hace décadas. Sin embargo, las políticas de control en la frontera marítima mediterránea se acentuaron recientemente, particularmente a partir de la creación de FRONTEX, tal como vimos en el apartado anterior. La puesta en práctica de los controles legales se expresa en el territorio con la construcción de muros tangibles e intangibles, que coexisten con intersticios que facilitan el ingreso de los inmigrantes. En este sentido, se puede afirmar que el número de inmigrantes irregulares que cruzan la frontera marítima sur, y de acuerdo con datos de FRONTEX 2013, varía según el área. En el Mediterráneo occidental (noroeste de África hacia España) se redujo un $13 \%$ el flujo de ingresantes entre 2012 y 2013; en el Mediterráneo oriental (Medio Oriente hacia Grecia y Europa del este) también la entrada de indocumentados disminuyó un $68 \%$; mientras que la ruta que se dirige desde el Cuerno de África a Italia, pasando por Egipto, creció un $13 \%$. Finalmente, la ruta del Mediterráneo central (Libia y Túnez hacia Italia) aumentó considerablemente, registrándose un $108 \%$ más de ingresos en 2013 respecto a 2012 (FRONTEX, 2013).

La aplicación de la política europea de migraciones en los países de la región mediterránea se combina con otros factores específicos, como las características geográficas de los territorios, su posición estratégica en los caminos de la migración desde África y la existencia de empleos informales en la estructura económica de Grecia, Italia y España, lo cual proporciona oportunidades de trabajo informal a los inmigrantes.

Una característica particular de la región mediterránea es la existencia de costas e islas, como Lampedusa, ubicada a $205 \mathrm{~km}$ de las costas de Sicilia y a $113 \mathrm{~km}$ de las costas de África del Norte. También las islas griegas en el Mar Egeo o las islas Canarias en el Atlántico actúan como puentes, pues se han transformado en lugares de llegada de lanchas, cayucos u otras pequeñas embarcaciones que transportan migrantes cuyo propósito es ingresar a Europa. "Europa empieza en Lampedusa", dice Bernard-Henry Lévy $^{13}$ (2013), refiriéndose a los naufragios y pérdidas de vidas humanas acontecidas en octubre de 2013 en proximidades de la isla, y manifiesta que “(...) lo más sorprendente $y$, en cierto modo, terrible de la interminable tragedia que simboliza hoy Lampedusa es la indiferencia con la que nosotros, ciudadanos de la Europa

13 Bernard-Henry Lévy, filósofo, manifiesta que "(...) lo que está en juego aquí es el destino de Europa; lo que está a prueba es la definición de Europa; lo que se tortura y se mortifica en cada uno de esos pequeños cuerpos horriblemente alineados y, a menudo, sin nombre, es el alma de Europa" (Lévy, 2013). 
opulenta, la estamos tratando" (Lévy, 2013). Indiferencia a la que también se refirió el Papa Francisco en su visita a la isla en julio de 2013, en la que visitó inmigrantes africanos. En dicho encuentro el Papa expresó:

¿Quién de nosotros ha llorado por la muerte de estos hermanos y hermanas, de todos aquellos que viajaban sobre las barcas, por las jóvenes madres que llevaban a sus hijos, por estos hombres que buscaban cualquier cosa para mantener a sus familias? Somos una sociedad que ha olvidado la experiencia del llanto... La ilusión por lo insignificante, por lo provisional, nos lleva hacia la indiferencia hacia los otros, nos lleva a la globalización de la indiferencia (Ordaz, 2013).

Las tragedias que se han sucedido durante años en proximidades de Lampedusa no son solo responsabilidad de políticos, traficantes $u$ otros actores con poder; la responsabilidad también alcanza a los que la contemplan con apatía. Esta isla, caracterizada por playas con arenas blancas y mar de color turquesa, debería ser, según Rafael Argullol (2013), como "la isla de los espíritus dolientes", espíritus de los cadáveres que yacen en el fondo del mar y que de algún modo esperan una vindicación, según el autor.

Las economías de Italia, Grecia y España se caracterizan por desequi- librios estructurales, así como por un amplio sector de empleo informal. "Estas características han sido importantes para la atracción de inmigrantes irregulares y permiten para ambos, legales e indocumentados, la supervivencia a pesar del control migratorio o el fortalecimiento de las políticas" (Triandafyllidou, 2009, p. 8). De acuerdo con los datos del Instituto Nacional de Estadísticas de España (2012), la cantidad de extranjeros en este país era en 2010 de 5.663.525 personas, lo que representaba el $12,3 \%$ sobre la población total; en Italia, la cantidad de extranjeros es de 4.235.059, es decir, el $7 \%$ de la población total, y en Grecia el número de extranjeros es de 954.784, el 8,4\% de la población total.

En el caso de Italia, y de acuerdo con lo expresado por Naïr (2006), el aporte de la mano de obra inmigrante a la economía de este país es muy importante. "De cada diez trabajadores uno es inmigrante. La contribución de estos a la riqueza nacional representa el $4 \%$ del PIB y 124.000 empresas individuales pertenecen a extranjeros" (Naïr, 2006, p. 118). Esta realidad indica que el funcionamiento de la economía de este país tiene un fuerte anclaje en los extranjeros.

La gestión de Italia frente a la llegada de inmigrantes plantea interrogantes a los controles fronterizos establecidos en el Espacio Schengen; esto se 
manifestó cuando Italia “(...) decidió una interpretación original de sus propias normas migratorias y conceder un permiso de residencia temporal por razones humanitarias a los inmigrantes tunecinos (claramente migrantes económicos) y a la vez documentarlos con un "documento de viaje de extranjeros" para, de esta forma, facilitarles el paso por el espacio Schengen" (González Enríquez, 2011, p. 4). Este acontecimiento tensionó las relaciones en el interior de la UE y puso a repensar las normas que rigen la libre circulación de ciudadanos en el mayor territorio internacional del mundo sin controles fronterizos.

Como consecuencia de la normativa vinculada con la temática de las migraciones, especialmente, a partir de la aplicación de la Directiva de Retorno, se profundizaron los controles sobre los migrantes indocumentados y se implementaron dispositivos de protección contra los desplazamientos de personas, lo que implica la creación de campos de agrupamiento y detención de personas que tienen en trámite su admisión o que esperan su expulsión. "Aislar a los extranjeros en el interior de las fronteras de la Unión Europea, tanto si se trata de campamentos abiertos (acogida, tránsito o alojamiento) como cerrados, es un fenómeno conocido que lleva aplicándose desde hace tiempo. Lo que es realmente nuevo es el hecho de sistematizarlo y deslocalizarlo hacia los países de origen o de tránsito" (Naïr, 2006, p.
154). Existen numerosos centros de "internamiento" y de características diferentes de acuerdo con su ubicación geográfica y con la función que cumplen en el entramado normativo de la Unión Europea. Están localizados fundamentalmente en las nuevas fronteras del Este -Hungría, Polonia, Ucrania-, pero también en Alemania, Francia y Reino Unido, así como en la región Mediterránea -Ceuta, Melilla, Malta y las islas de Lampedusa y Sicilia-, en las Islas Canarias, en Argelia y en Turquía ${ }^{14}$.

De acuerdo con lo expresado, el Mediterráneo cumple un rol de contacto entre el Norte y el Sur en relación con la dinámica de los flujos migratorios. Este contacto se manifiesta en el territorio a través de encuentros, tránsito, intercambios transfronterizos $\mathrm{y}$ también tensiones y conflictos. Por su parte, esta región constituye una "(...) fractura -política, comercial, cultural, económica, social y demográfica- no solo entre los países ribereños del Sur y del Norte, sino más profundamente aún en el seno del propio sur, cuya brecha geopolítica se extiende hoy hasta África subsahariana y se amplía por el este, hacia Turquía, y muy pronto, hacia Asia Occidental" (Naïr, 2006, p. 60).

La mirada desde una perspectiva de la geografía contemporánea permite

\footnotetext{
14 La distribución territorial de estos centros puede consultarse en la cartografía del artículo "Convertir a los países ricos en fortalezas", publicado en El Atlas II, Le Monde Diplomatique 2006, p. 51.
} 
analizar la jurisdicción y la soberanía de los Estados e interpretar que la externalización de las políticas migratorias implica un refuerzo del control de las fronteras, tanto en los Estados miembros de la Unión Europea integrantes del Espacio Schengen, como en los Estados de origen y de tránsito de los migrantes. Asimismo, esto significa una interferencia y una reducción de la soberanía de los Estados de origen de los migrantes, dado que se interviene directamente sobre las costas y los límites terrestres. En este sentido, si el control de las fronteras es uno de los pilares básicos de la soberanía de un Estado, la externalización de las políticas de migraciones impone una transformación, “(...) esto implica una ruptura en los fundamentos de las existentes teorías de fronteras" (Zaragoza, 2012, p. 157). Los Estados de la Unión Europea actúan directamente en el control fronterizo o, lo que es lo mismo, interfieren en la soberanía de los Estados de origen y de tránsito de los migrantes, y reconfiguran las relaciones geopolíticas $^{15}$.

15 "La geopolítica se establece en una relación de poderes entre países, ya que se trata de una definición del mundo y de las acciones políticas orientadas hacia los individuos, por las cuales se ven afectados los migrantes en este desarrollo divisorio del mundo, habrá lugares permitidos y otros prohibidos o de mayor dificultad en base a los intereses existentes, los cuales son múltiples y muchas veces contrapuestos. Esto producirá un quiebre entre el imaginario del flujo liberador de la globalización y la realpolitik de los Estados en cuanto a la defensa de sus intereses" (Aliaga Sáez, 2012, p. 10).
La externalización de las políticas migratorias incluye acciones como la lucha contra las causas de la migración y el vínculo migración-desarrollo, la promoción de medidas para la migración laboral y las políticas de admisión. Estas acciones implementadas por la Unión Europea están articuladas con la cooperación respecto al control de la migración irregular que desarrollen los países de origen de los migrantes, e incluso los países de tránsito. Cabe preguntarse si efectivamente son políticas cuyo propósito apunta a la erradicación de la marginalidad y la pobreza. Diversos autores analizan esta cuestión, que se puede sintetizar en dos aspectos más destacados; por una parte, la coherencia/articulación entre la ayuda al desarrollo y las políticas migratorias no tiene credibilidad suficiente, y, por otra parte, la ayuda al desarrollo se canaliza hacia países que en general están gobernados por regímenes autoritarios, donde no se respetan los derechos humanos básicos. Esta última situación da más poder a los gobiernos para reprimir y controlar los movimientos de población y no se resuelven los problemas socioeconómicos que impulsan a las personas a tomar la decisión de cruzar las fronteras (Shmite, 2015).

Una contradicción entre transnacionalización económica y control de fronteras es el contexto en el que se 
desarrollan las migraciones actuales desde África hacia Europa. De acuerdo con lo expresado por Saskia Sassen (2013), la integración de la UE aumentó la libertad de circulación de las personas y la actividad económica transnacionalizada, pero al mismo tiempo se acrecentó el control de la migración, acentuando cada vez más la diferenciación entre ciudadanos comunitarios y extracomunitarios.

\section{Reflexiones finales}

El Mediterráneo es una región de frontera que está constituida por un conjunto de países con fuertes asimetrías, tanto desde la perspectiva económica como desde la perspectiva político-institucional y cultural. El avance de la integración económica de la UE no ha hecho más que incrementar la polarización entre los países localizados al Norte y al Sur. El Mediterráneo ha sido, y sigue siendo, una frontera con fuertes desequilibrios, y requiere de estrategias políticas para gestionar los flujos migratorios que llegan desde el sur. El abordaje de los movimientos migratorios en el Mediterráneo permitió comprender por qué no se detienen, a pesar de las políticas migratorias restrictivas y de los controles de frontera. La geografía de los flujos migratorios permite interpretar que la dinámica poblacional está articulada directamente con las decisiones geopolíticas y económicas de los pro- pios Estados, situación que genera controles cada vez más estrictos, ciudadanos de diferentes categorías, oportunidades y también nuevas formas de desigualdad, denominadas por Sassen (2015) expulsiones.

La UE ha impulsado el desarrollo de políticas migratorias que terminan tensionando los derechos ciudadanos dentro de la unidad supranacional y ha generado un aumento de la discriminación hacia los inmigrantes, particularmente los indocumentados. En este sentido, la frontera del Espacio Schengen se configura como un espacio de control sobre los flujos migratorios, complementado con las acciones articuladas por la Agencia Europea para la Gestión de la Cooperación Operativa en las Fronteras Exteriores (FRONTEX). De este modo, la construcción de un espacio supranacional como la UE, que impulsa la libre circulación de los ciudadanos europeos, derivó en el ejercicio de una soberanía territorial articulada por una trama jurídica cada vez más restrictiva sobre los inmigrantes, denominados ciudadanos de terceros países, y también la creación de un organismo de control efectivo (FRONTEX) para frenar el ingreso de migrantes. Esto evidencia la necesidad de ejercer acciones directas (patrullaje terrestre, aéreo y marítimo, vigilancia con cámaras, construcción de vallados y de murallas, etc.) para gestionar la soberanía 
territorial de la UE, resguardar los propios intereses y lograr, de este modo, una integración funcional en la economía global. Estas estrategias de control no hacen más que impedir el ingreso e, incluso, implementar el retorno de los inmigrantes, en lugar de contribuir al desarrollo económico-social de los territorios al sur del Mediterráneo.

La dicotomía Norte-Sur debería articularse a partir de políticas que favorezcan el trabajo conjunto de los Estados involucrados en esta dinámica migratoria. Solo un trabajo de gestión integrada permitiría demoler las barreras, resolver las fracturas y comenzar un camino que priorice los derechos humanos de todos los ciudadanos y la equidad de oportunidades.

Europa vive una fuerte contradicción entre el envejecimiento de la población, que genera demanda de mano de obra, y el control del ingreso de la población extranjera. La mayoría de los Estados europeos combina dos extremos demográficos: elevada esperanza de vida y reducida tasa de natalidad. Por lo tanto, la relación entre población activa y población pasiva en las próximas décadas será aún más negativa que en la actualidad. La movilidad laboral desde países extranjeros podría equilibrar el descenso de la población económicamente activa; sin embargo, la migración es percibida como un pro- blema en el contexto actual de la crisis económica que atraviesa Europa, donde las tasas de desempleo siguen en aumento. Esta situación no hace más que aumentar la tensión entre los migrantes que ingresan en busca de un empleo y la fuerza laboral local.

Es posible que, tal como considera la Organización de Naciones Unidas (ONU), el proceso de globalización esté ingresando en una etapa que, tras la liberalización del tráfico de capitales y bienes, se introduzca en una nueva «era de la movilidad», en la que la emigración internacional sea reconocida como un derecho humano más. Así lo afirma Peter Sutherland ${ }^{16}$ (2007), representante especial para Migración del Secretario General de la ONU. En este sentido, Kabunda Badi (2008) sostiene que los migrantes africanos sufren una doble discriminación y exclusión tanto en los países receptores o de llegada, como en los países emisores o de origen, $\mathrm{y}$, por lo tanto, no se les respetan los derechos humanos básicos.

Desde la perspectiva de la geografía crítica, pensar el espacio geográfico como un complejo entramado permite visualizar los diferentes actores y sus lógicas territoriales. La dimen-

16 Ricardo Martínez de Rituerto, autor del artículo "La ONU considera la migración un derecho que debe ser regulado", hace referencia al Primer Foro Global sobre Migración y Desarrollo, celebrado en Bruselas en julio de 2007, donde Sutherland se refiere a la movilidad de la población y a los derechos de los migrantes. 
sión histórica de la problemática de las migraciones a escala de la región mediterránea y la dinámica de los acontecimientos actuales, así como la impronta en los medios de comunicación, estimula la exploración de las diversas perspectivas de esta la realidad existente. realidad. En este artículo se intentó aportar al conocimiento de la dimensión socio-política y normativa de las migraciones transmediterráneas, con el propósito de contribuir a la construcción de un pensamiento geográfico que guíe la transformación de

\section{Referencias}

Algado Ferrer, M.T. \& Ruiz Callado, R. (2009). El desarrollo humano y los movimientos migratorios en las culturas mediterráneas. PAPERS, 94, 155-169. Recuperado de: www.raco.cat/index.php/Papers/article/download/159827/211717

Aliaga Sáenz, F. A. (2012) Imaginarios migratorios y geopolítica en sociedades posmodernas. En Imagonautas, 1(2), 2-20. Recuperado de: www.dialnet.unirioja.es/descarga/ articulo/4781512.pdf

Álvarez Acosta, M. E. (Coord.) (2011). África Subsahariana. Sistema Capitalista y relaciones internacionales. Buenos Aires: CLACSO.

Argullol, R. (2013, 16 de octubre). La isla de los espíritus dolientes. Diario El País. Recuperado de: http://elpais.com/elpais/2013/10/13/opinion/1381691360_326895.html

Bourdieu, P. (2008). Las estructuras sociales de la economía. Buenos Aires: Manantial (3. ${ }^{\circ}$ reimpresión).

Brumat, L. (2013). Políticas migratorias, construcciones de identidad europea y el inmigrante como una "amenaza". Un análisis de la Directiva de Retorno. Revista Diversidad, 4(6). Recuperado de: http://cimal.iom.int/sites/default/files/06-01-leiza-brumat.pdf

Cheru, F. (2008). Globalización y urbanización desigual en África. En L. Delcourt et al., Explosión urbana y globalización. Madrid: Popular.

Coleman, J, (1990). Fundations of Social Theory. Cambridge: Harvard University Press.

Crespo Ubero, R. (2006). Rutas migratorias Transaharianas: de los puertos caravaneros a los cayucos. Revista Nova África, 19, 77-93. Recuperado de: http://www.novaafrica. net/documentos/archivo_NA19/04NA19.Crespo77-94.pdf

De Haas, H. (2007). Le mythe de l'invasion. Migration irrègulèire d'África de l'Ouest au Magrhreb et en Union eurpéenne. Intenational Migration Institute. 1-81. University of Oxford. Recuperado de: http://www.imi.ox.ac.uk/pdfs/reports/mythe-1-invasion.pdf

Durston, J. (2000). ¿Qué es el capital social comunitario? CEPAL Serie Políticas Sociales, 30, 1-44. Recuperado de: www.repositorio.cepal.org/bitstream/11362/5969/1/ S0007574_es.pdf

Durston, J. (2002): El capital social campesino en la gestión del desarrollo rural. Díadas, equipos, puentes y escaleras. Chile: Naciones Unidas. Recuperado de: http://archivo. 
cepal.org/pdfs/2002/S2002033.pdf

El ATLAS II (2006). Le Monde Diplomatique. Buenos Aires: Capital Intelectual.

EUROSTAT (2010). Complete database, Recuperado de: www.eurostat.ec.europa.eu.

Fernández, M. (2008). Diáspora: la complejidad de un término. Revista Venezolana de Análisis de Coyuntura, XIV(2), 305-326. Recuperado de: http://www.redalyc.org/ articulo.oa? id $=36414217$

Ferrer-Gallardo, X. \& Kramsch, O. T. (2012). El archipiélago-frente mediterráneo: fractura, ensamblaje y movimiento en el contorno sur de la UE. 79-102. En R. Zapata Barrero \& X. Ferrer Gallardo. (Eds.), Fronteras en movimiento. Migraciones hacia la Unión Europea en el contexto Mediterráneo. Barcelona: Bellaterra.

Frattini, F. (2007). La política de migración de la UE: del Programa de La Haya a los importantes logros actuales. En J. Borrell Fontells (Coord.), Europa en la Encrucijada. Revista Mediterráneo Económico, 12, 191-200. Recuperado de: http://www. publicacionescajamar.es/pdf/publicaciones-periodicas/mediterraneo-economico/12/ mediterraneo-economico-12.pdf

FRONTEX (2013) - Agencia Europea para la Gestión de la Cooperación Operativa en las Fronteras Exteriores. Recuperado de: http://frontex.europa.eu/assets/Publications/ Risk_Analysis/FRAN_Q2_2013.pdf

González Enriquez, C. (2011). ¿Schengen en peligro? Real Instituto Elcano, España Documento ARI 88, 1-6. Recuperado de: http://www.realinstitutoelcano.org/wps/ portal/web/rielcano_es/contenido?WCM_GLOBAL_CONTEXT=/elcano/elcano_es/ zonas_es/demografīa-y+poblacion/ari8̄-2011

Kabunda Badi, M. (Coord.) (2012). África en Movimiento. Migraciones Internas y Externas. Madrid: Los Libros de la Catarata.

Kabunda Badi, M. (2008). Inmigración y desarrollo: el caso africano. Revista Nova África, 23, 1-24. Recuperado de: http://centredestudisafricans.org/estudis-africans/

Kabunda Badi, M. (2006). La Inmigración Africana, revisada. Revista Nova África, 18, 19-39. Recuperado de: http://centredestudisafricans.org/estudis-africans/

Lévy, B. (2013, 3 de noviembre). Europa empieza en Lampedusa. Diario El País. Recuperado de: http://elpais.com/elpais/2013/10/31/opinion/1383217903_787270.html

Martínez de Rituerto, R. (2007, 11 de julio). La ONU considera la emigración un derecho que debe ser regulado. Diario El País. Recuperado de: http://elpais.com/diario/2007/07/11/ internacional/1184104806_850215.html

Naïr, S. (2006). Y vendrán... las migraciones en tiempos hostiles. Barcelona: Planeta.

Ordaz, P. (2013, 1 de julio). El Papa clama en Lampedusa contra "la globalización de la indiferencia”. Diario El País. Recuperado de: http://internacional.elpais.com/ internacional/2013/07/08/actualidad/1373270412_332935.html

Organización Internacional para las Migraciones -OIM- (2011). Informe sobre las migraciones en el mundo 2011. Recuperado de: www.publications.iom.int

Organización Internacional para las Migraciones -OIM- (2013). Informe sobre las 
migraciones en el mundo 2013. Recuperado de: www.publications.iom.int

Papadodima, Z. Las fronteras regionales: la materia de migraciones en la Geopolítica contemporánea. Cuadernos Geográficos, 48, 189-205. Recuperado de: http://www. redalyc.org/pdf/171/17121091007.pdf

Real Academia Española -RAE- (2015). Recuperado de: http://dle.rae.es/?id=PE38JXc

Sassen, S. (2015). Expulsiones. Brutalidad y complejidad en la economía global. Madrid: Katz.

Sassen, S. (2013). Inmigrantes y ciudadanos. De las migraciones masivas a la Europa fortaleza. Madrid: Siglo XXI.

Shmite, S. M. y Nin, M. C. (2015). África al sur del Sahara: conflictos y degradación ambiental en el Sahel. Revista Colombiana de Geografía, 24(2), 205-219. Recuperado de: http://www.revistas.unal.edu.co/index.php/rcg/article/view/50221

Shmite, S. M. (2015). Migraciones, derechos humanos y políticas de la Unión Europea. 191-223. En A. F. Alonso, M. C. Nin \& S. M. Shmite, Unión Europea. Proceso histórico y desafíos actuales. Santa Rosa: EdUNLPam.

Sow, P. (2007). Diásporas africanas y mundialización: de la representación histórica a la toma de conciencia. En F. Iniesta (Ed.), Movimientos de población y políticas estatales. 135-150. Barcelona: CIDOB. Recuperado de: www.cidob.org/es/content/ download/.../16-AFRICA+EN+DIASPORA.pdf

Triandafyllidou, A. (2009). Políticas de control en Europa del Sur. ¿Una tarea de Sísifo? Revista Miradas en Movimiento, 2, 6-33. Recuperado de: www.dialnet-PoliticasDeC ontrolEnEuropaDelSurUnaTareaDeSisifo-3090339\%20(2).pdf

Zamora, J.A. (2003). Globalización y migraciones. Una mirada desde Europa solidaria con el Sur. Realidad, 95, 623-646. Recuperado de: www.dialnetGlobalizaciones YMigraciones-4025488\%20(3).pdf

Zaragoza Cristiani, J. (2012). Justicia global y externalización de políticas migratorias: el caso español. En R. Zapata-Barrero \& X. Ferrer-Gallardo. (Eds.), Fronteras en movimiento. Migraciones hacia la Unión Europea en el contexto Mediterráneo, 143173. Barcelona: Bellaterra. 
Recepción: 23 de junio de 2015

Evaluación: 18 de octubre de 2015

Aprobación: 15 de noviembre de 2015 